\title{
Asymptotic and boundedness behaviour of a rational difference equation
}

\section{ABSTRACT}

In this work, we investigate the asymptotic behaviour and examine boundedness of the solutions for the following difference equation $\mathrm{xn}+1=\alpha \lambda-(\mathrm{nxn}+(\mathrm{n}-\mathrm{k}) \mathrm{xn}-\mathrm{k}) \beta+\mathrm{nxn}$ $+(\mathrm{n}-\mathrm{k}) \mathrm{xn}-\mathrm{k}, \mathrm{n}=0,1,2, \ldots$ (1) where $\lambda \geq 1$ and $\alpha, \beta \geq 0$ and $\mathrm{x}-\mathrm{k}, \mathrm{x}-(\mathrm{k}-1), \ldots, \mathrm{x}-1, \mathrm{x} 0$ are arbitrary numbers.

Keyword: Equilibrium point; Asymptotic stability; Boundedness; Positive solutions 
